\title{
Mesh Brachytherapy
}

National Cancer Institute

\section{Source}

National Cancer Institute. Mesh Brachytherapy. NCI Thesaurus. Code C106078.

An internal radiation treatment technique in which a piece of thin, flexible mesh made of vicryl and implanted with radioactive seeds is surgically attached to target tissue where it emits a low dose of radiation over a prolonged period of time. 